BAIEF SUMMARY OI PRESCRIBING INFOAMATIOH
INDICATIONS AMD USAGE

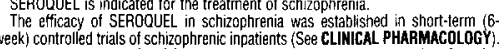
The eflectiveness of SEROQUEL in long-term use, that is. for more than 6 weeks,
has not been systematically evaluated in controlled trials. Thereferese, the physician the long-term usetulness
conTRAMDICATIONS

medication or any of its ingredients. Neuroloptic Malignant Syndrome: (NMS) A potentially fatal symptom complex

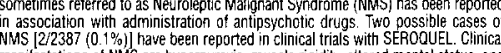

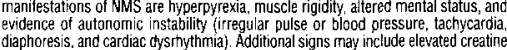
phosphokinase, myoglobinuria (rhabdomyolysis) and acute renal failure. The diag-
nostic evaluation of patients with this syndrome is complicated in arrivino at a diagnosis, it is important to exclude cases where the clinical presentation includes
both serious medical illness (e.q., pneumonia. Systemic infection, etc.) and untreated or inadequately treated extrapyramidal signs and symptoms (EPS). Other importan heat stroke, drug fever and primary central nervous system (CNS) pathology. The management of NWLS should include: 1 ) immediate discontinuation of antipgychotic rraatment and medical monitoring; and 3 i) treattment of any concomitant serious agreement about specific pharmacological treatment regimens for NMS. If a patien requires antipsychotic drug treatment after recovery from NMS, the potential reircarefully monitored since recurrences of NMS have been reported. Tardive
Oyskinesia: A syndrome of potentially irreversible, involuntary, dyskinetic move-
ments may develop in patients treated with antipsychotic drugs. Although the prevalence of the syndrome appears to be highest among the elderly, especially
elderily women, it is impossible to rely upon prevalence estimates to predict. at the

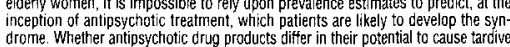
dyskinesia is unknown. The risk of developing tardive dyskinesia and the likelihood increase. However, the syndrome can develop, atthough much less commonly, atter relatively brief treatment periods at low doses. There is no known treatment tor
esstablished cases of tardive dyskinesia. although the syrdrome may remit, partially itselt, howeverer, may supporess (or partially suppressis the signs anc symptoms of the
syndrome and thereby may possitly mask the underlying process. The effect that symptomatic suppression has upon the long-term course of the syndrome is
unknown. Given these considerations, SEROOGUEL should be prescribed in a manner that is most likely to minimize the occurrence of tardive dyskinesia. Chronic antipsy-
chotic treatment should generally be reserved for patients who appear to suffer from a chronic illness that (1) is known to respond to antipsychotic drugs, and (2) tor
whiom alternative, equally effective, but potentially less harmifil treatments are not available or appropriate. In patients who do require chronic treatment, the smallest
dose and the shortest duration of treatment produciting a satisfactory clinical
response should be sought. The need tor continued treatment should be reassessed periodically. If signs and syimptorns of tardive dyskinesia appear in a patient on
SEROCUUEL, drug discontinuation shoult be considered. However, some patients may require treatment with
PRECAUTIONS: General

Orthostatitc CHypotension: SEROQUEL may induce orthostatic hypotennion associated with dizziness, tachycardia and in some patients, syncope, especially during
the initial dose-fitration period, probably reflecting its $\alpha$-adrenergic antagonist properties. Syncope was reported in $1 \%$ (22/2162) of the patients treated with active controt drugs. The risk of orthostatic hypotension and syncope may b
minimizized by limiting the initial dose to $25 \mathrm{mg}$ bid. If hypotension occurs during litration to the target dose. a refurn to the previous dose in the tiritation schedule
is appropriate. SEROOLUEL should be used with particular caution in patients with is appropriate. SEROdEL snould be used with particular caution in patients with
knowr cardiovascular disease (history of myocardial intarction or ischemic hear

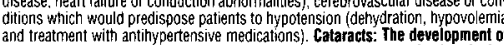
cataracts was observed in association with quetiapine treatment in chronic do

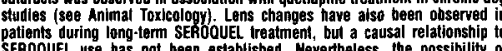
SERDOUEL use has not baen establisher. Hevertheless, the possibility o lenticular changes camnot be excluded at this time. Theretore, examination of axam or other appropratalely sensitive methods, is recommended at intiation reatment or shortly therealter, and at 6 month intervals during chronic treatment Selzures: During clinical trials, seizures occurred in $0.8 \%$ (18/2387) of patients
treated with SEROOUEL compared to $0.5 \%$ (11206) on placebo and $1 \%$ (4/420) on

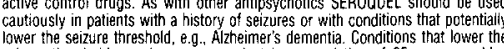
seizure threshold may be more prevalent in a population of 65 years or older
Hypothyroidism: Clinical trials with SEROQUEL demonstrated a dose-relater decrease in total and free thyroxine (T) of approximately $20 \%$ at the higher end of
the therapeutic dose range and was maximal in the first two to four weeks of treatmetht and maintained wittout adaptatition or pr progresssion duringn more chronic therapy
Generally, these changes were of no clinical significance and TSH was unchanged

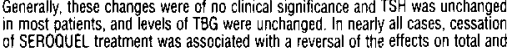

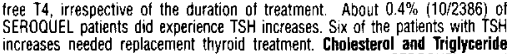
increases needed replacement thyroid treatment. Cholesterol and Triglyceride $17 \%$, respectivety, comparad to slight decreases sor placebo patients. These

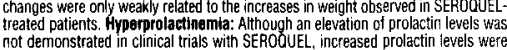
not dernenstrated in clinical trials with in mammary pland neoplasia in rats (see Carcinogenesis). Tissue culture experi-
ments indicate that approximately one-third of human oreast cancers are prolactin

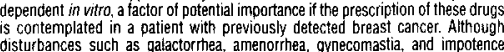
disturbances such as galactorthea, arnenor rhea, gynecomastia, and impotence have been feported with prolactin-etevating compounds, the clinical significance of
elevated serum prolactin levels is unkrown for most patients. Neither clinical studies chromic administration of this class of drugs and tumorigenesis in humans; the
available evidence is considered too limited to be conclusive at this time Iransaminase Elevations: Asymptomatic, transient and reversible elevations in serum transaminases (primarily ALT) have been reported. The proportions of
patients with transaminase elevations of $>3$ times the upper limits of the norma mately $6 \%$ for SEROOUEL compared to $1 \%$ for placebo. These hepatic enzyme

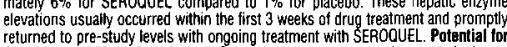
Cognilive and Motor Impairment: Somnolence was a commonnly reported adverse
event reported in patients treated with SEROQUUEL especially during the $3-5$ day

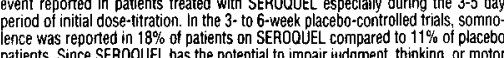
lence was reported in $18 \%$ of patients on SEROQUEL COmpared to $11 \%$ of placebo
patients. Since SEROOUEL has the potential to impair iudgment, thinking or motor
skills, patients should be cautioned about performing activities requiring mental

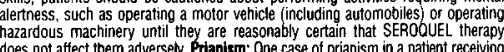
does not antect them adversery. Priapism: One case of priapism in a patient recelving
$S E R O O U E L$
has been reported prior to market introduction. While a causal relation. ship to USe of SEROQUEL has not been established, other drugs with
alpha-adrenergic blocking etfects have been reported to induce priapism, and it is

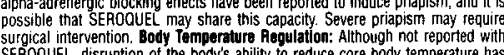
been attributed to antipsychotic agents. Appropriate care is advised when prescribing
SEROOUEL tor patients who will be experiencing conditions which rmay contribute to an elevation in core body temperature, e.g., exercising strenuously, exposure to

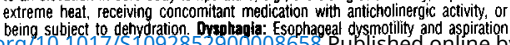

SEROQUEL ${ }^{\oplus}$ (quetiapine fumarale) Tablets

have been associated with antipsychotic drug use. Aspiration pneumonia is a common advanced Alzheimer's dementia. SEROQUEEL and other antipsychotic drug should be used cautiously in patients at risk tor aspiration prieumonia. Suicidide: of high risk patents should accompany drug therapy. Prescriptions for SEROQUEL
should be writter tor the smallest quantity of tablets consistent with o0od patient

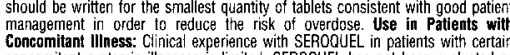

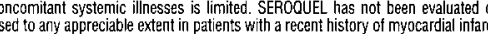
tion ar unstable heart disease Patients with these diannoses of myocardial infarcDremarketing clinical studies. Because of the risk of orthostatic typotension with
SERDOUIEL, caution should be observed in carciac patients (see Orthostatic Hypotensions. Intormation Jor Patients: Physicians are advised to discuss the
following issues with patients for whom they prescribe SEROQUEL. Orthostatic Iollowing issues with patients for whom they prescribe SERDQUUEL. Orhostatic
Hypotension: Patients should be advised of the risk of othostatic hypotension ce-initiating treatment or iffreases in dose. Interterence with Cognitive and Motor Pertormance: Since sormnolence was a commonly reported adverse evert associated with SEROQUEL treatment, patients should be advised of the risk of somnolence,
especially during the $3-5$ day period of initial cose titration. Patients shculd be a motor vehicle (including automobiles) or operating hazardous machinery, unitil Pregnaaney. Patients should be advised to notify their physician it they beccome creg.
nant or intend to become pregnant during therapy. Nursing: Parients should be advised not to breast feed if they are taking SEROOUEL. Concomitant Medication they are taking, or plan to take, any prescription or over-the-counter drugs. Alcohio SEROQUUEL. Heat Exposure and Dehydration: : Patients should be advised regarding appropriate care in avoicing overheating and dehydration. Laberatory Tests: No
specitic laboratory tests are recommended. Drug Interactions: The risks of using SERQQUEL in combination with other drugs have not been extensively evaluated in
yystematic studies. Given the primary CNS ettects of SEFOOUEEL, caution Shlould be used when it is taken in combination with other centrally acting drugs. SEROQUEL
potentiated the cognitive and motor effects of alcohol in a clinical trial in subjects with selected psychotic disorders, and aicoholic beverages should be avoided while
taking SEROQUEL. Because of its potential tor inducing hypotension, SEROOUEL may enhance the effects of certain antihypertensive agents. SEROOUEL may antagSEROQUEL Phenytoin: Coadministration of quetiapine $i 250 \mathrm{mg}$ tid) and phenytoin
(100 mg tid) increased the mean oral clearance of quetiapine by 5 -fold. Increased doses of SEROCUEL may be required to maintain control of symptoms of schizo-
phrenia in patients receiving quetiapine and phenytoin, or other hepatic enzyme chould be taken if phenytoin is withdrawn and replaced with a non-inducer (e.g. valproate). Thioridazine: Thioridazine $1200 \mathrm{mg}$ bid) increased the oral clearance of

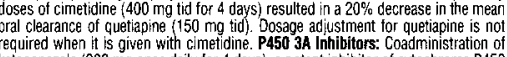
ketoconazole (200 mg once daily for 4 days), a potent inhibitor of cytochrome P45
$3 \mathrm{~A}$, reduced oral ciearance of quetiapine by $84 \%$, resulting in a $335 \%$ increase
maximum plasma concentration of quetiapine. Caution is indicated when SEROOUE

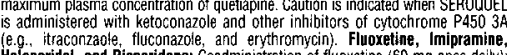
imipramine $(75 \mathrm{mg}$ bid), haloperidol ( $7.5 \mathrm{mg}$ bid), or risperidone ( $3 \mathrm{mg}$ bid) vit)

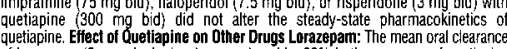
of lorazeparn (2 m, single dose) was reduced by $20 \%$ in the presence of quetiapine
administered as $250 \mathrm{~mm}$ tid dosing. Lithium: Concomitant administration of queliapine (250 mg tid/ with littiumn had no effect on any of the steady-state

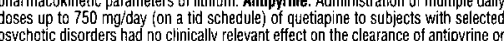
urinary recovery of antipyrine metabclites. These results indicate that quetiagine mediated metatolism of antipyrine. Carcinogenesis, Mutagenesis, Impairment of Fertility Carcinogenesis: Carcinagenicity studies were conducted in $C 57 B L$ mic
and Wistar rats. Quetiapine was acministered in the diet to mice at doses of 20,75 ,

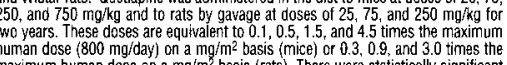
maximum human dose on a mg $/ \mathrm{m}^{2}$ basis (rats). There were statistically significant

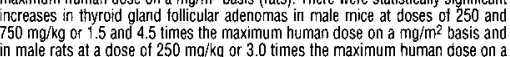
in male rats at a dose of $250 \mathrm{mg} / \mathrm{kg}$ or 3.0 times the maximum human dose on a
mg $\mathrm{m}^{2} \mathrm{~m}^{2}$ asasis. Mammary gland adencoarcinomas were statistically signiticantly increased in temale rats at all doses tested $(25,75$, and $250 \mathrm{mg} / \mathrm{k}$ or $0.3,0.9$, and
3.0 times the maximum recommended human dose on a mg/m
basis $)$. Thyroid tollicular cell adenomas may have resulted from chronic stimulaticen of the thyroid
gland by thyroid stimulating hormone (TSH) resulting from enthanced metabolism and ciearance of thymroxing by rordente liver Changes in TSH, thyroxine, and thyoroxine clearance consistent with this mechanism were observed in subchronic loxicity
studies in rat and mouse and in a 1-year toxicity study in rat, however, the results
of these stutilies wera not definititive. The relevance of the increasess in thyroid follicular cell adenomas to human risk, through whatever meachanism, is unkown
Antipsychotic drugs have been shown to chronically elevate protactin levels in
rodents. Serum measurements in a $1-y$-y toxicity study showed that quetiapine rodents, Serum measurements in a 1-yr toxicity study showed that quetalapine
increased median serum prolactin levels a maximum of 32 -and 13 -told in mala and
female rats, respeectively. Increases in mammary neoplasms have been found in rodents after chronic administration of other antipsychotic crugs and are considere to be proiactin-mediated. The relevance of this increased incidence of prolactin-
mediated mammary glannd tumors in yats to human risk is unknown (see
Hyperprolactinemia in PRECAUTIONS, General). Mutagenesis: The mutagenic potential of quetiapine was tested in six in vitro bacterial gene mutation assays and Sall tester strains. Quetiapine did produce a reproducible increase in mutaticicns in one evidence of clastogenic potential was obtained in an in vitro chromosomal aberration
assay in cultured human lymphocytes or in the in wivo micronucleus assay in rats. mpairment of Fertilitiv: Ouvetiapine decreased mating and fertility in mase Spraguehuman dose on a mg/m² basis. Drug-related effects included increases in interval effects continued to be observed at $150 \mathrm{mg} / \mathrm{kg}$ even after a two-week period withou Ireatment. The no-effect dose for impaired mating and fertility in male rats was
$25 \mathrm{mg} / \mathrm{kg}$, or 0.3 times the maximum human dose on a mg/m2 basis. Quetiapine adversely aftected mating and fertility in fernale Sprague-Dawtey rats at an oral dose
of $50 \mathrm{mg} / \mathrm{kg}$, or 0.6 times the maximum human dose on a $\mathrm{mmg}^{\mathrm{m}} \mathrm{m}$ basis. Drug-related

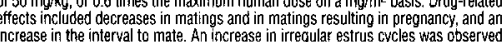
increase in the interval to mate. An increase in irregular esirus cycles was coserved
at dosesef of 10 and $50 \mathrm{mg} / \mathrm{kg}$. or 0.1 and 0.6 times the maximum humanan dose on a
$\mathrm{mg} / \mathrm{m}^{2}$ basis. The no-effect dose in female rats was $1 \mathrm{mg} / \mathrm{kg}$, or 0.01 times the maximum human dose on a mg/ $\mathrm{m}^{2}$ basis. Pregnancy: Pregnancy Category $\mathrm{C}$ : The dosed during the period of organogenesis. No evidence of a teratogenic effect was
deterted in rats at doses of 25 to 200 mgnkg or 0.3 to 2.4 times the maximum human dose on a mo/m ${ }^{2}$ basis or in rabbits at 25 to $100 \mathrm{mg} / \mathrm{kg}$ or 0.6 to 2.4 times the
maximum human dose of a mg/m2 $\mathrm{m}^{2}$ basis. There was, however, evidence of caximum human iose on a mg/m² basis. There was, however, evidence of
embryofftal toxicitiv. Delays in skeietal ossitication were detected in rat fetuses at

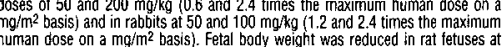
human dose on a $\mathrm{mg} / \mathrm{m}^{2}$ basis). Fetal body weight was reduced in rat fetuses at
$200 \mathrm{mg} / \mathrm{kg}$ and rabbit tetuses at $100 \mathrm{mg} / \mathrm{kg}(2.4$ times the maximum human dose on a mg/me basis for both species). There was an increased incidence of a minor
soft tissue anomaly (carpaltharsal flexure) in rabbit fetuses at a dose of $100 \mathrm{mg} / \mathrm{kg}$ (2.4 times the maximum human dosu en a mg/m2 $\mathrm{m}^{2}$ basisis). Evidence of maternal tox.
icity (i.e., decreases in body weight gain and dor death) was observed at the high

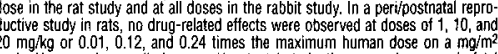

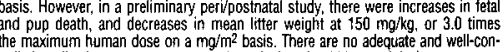

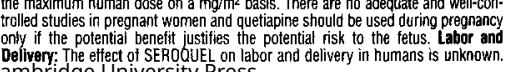

SEROQUEL (quetiapine fumarate) Tablets

Nursing Mothers: SEROOUEL $L$ was excreted in milk of treated animals during lactaWomen receiving SEROQLEEL sheuld not breast feed. Peddlatric Use The satety and were 65 years of age or over. In general, there was no indication of any different presence of tactors that might decrease pharmacokinetic clearance, increase the pharmacodynamic response to SEROQUEL, or cause pcorer tolerance or orthostasis,
should lead to consideration of a lower starting dose, slower titration, and careful monitoring during the initial dosing period in the elderly. The mean plasma clearance
of SEROQUEL was reduced by $30 \%$ to $50 \%$ in elderly patients when compared to YOUVERT patients.

Adverse Events Occurring at an Incidence of $1 \%$ or More Among SEROQUEL freated Patients in Shon-Term, Placeho-Cantrolled Trials: The most ccmmonly reater) and observed at a rate on SEROQUEL at least twice that of placebo were The following treatment-emergent adverse expefiences occurred at an incidence rate treated at doses of $75 \mathrm{mg} / \mathrm{day}$ or greater than among placebo treated patients in Body as a Whole: Headache, Asthenia Abdominal pain, Back pain, Fever; Nervous
System: Somnolence, Dizziness: Digestive System: Constioation, Dry Mouth, System: Somnolence, Dizziness; Digestive System: Constipation, Dry Mouth,
Dyspepsia Cardiovascular System: Postural hypotension. Tachycardia; Metabolic
and Nutritional Disorders: Weight gain; Skin and Appendages: Rash; Respiratory System: Rhinitis; Special Senses: Ear pain
Events tor which the SEROCLIEL incidence was equal to or less than placebo are "Events for which the SEROClEL incidence was equal to or less than placebo are
mot listed in the table, but included the following: pain, infection, chest pain, hostitity,

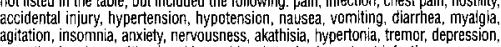
paresthesia, pharyngitis, cry skin, amblyopia and urinary tract infection. winically meanirgful differences in the adverse event occurrence on the basis of thes Placebo-Controfled Trials Dose-related Adverse Events: Spontaneously elicited $150 \mathrm{mg}, 300 \mathrm{mg}, 600 \mathrm{mg}$, and $750 \mathrm{~m}$ midday) to placebo were explored for doseesponse (p<0.05) for the following adverse events: dyspepsia, abdominal pain, and weight gain. Extrapyramiidal Symptoms: Data from one 6-week cinical trial comparing the lack of Ireatment-emergent extrapyramidal symptoms (EPS) and dose-relatedress
tor EPS associated with SEROQUEL treatment. Three methods were used to measure Park (1) Simpson-Angus total score (mean change from baselinej which evaluates
parkonism and akathisia, (2) incidence of spontaneous comptaints of EPS (akathisia, akinesia, cogwheel rigidity, extrapyramidal syndrome, hypertonia, hypoki-
nesia, neck nigidity, and tremor), and (3) use of anticholinergic medications to treat emergent EPS. In three additional placebo-controlted clinical trials using variable
doses of SEROOUEL, there were no differences between the SEROOUEL and placebo lreatment grcups in the incidence of EPS, as assessed by Simpson-Angus total
scares, spontaneous complaints of EPS and the use of concomitant anticholinergic medications to treat EPS. VItal Sign Changes: SEROQUEL is associated with ortho-
static hypotension (seP PRECALTIONS) Whilght Gain: The proportions of patients meeting a weight gain criterion of $27 \%$ of body weight were compared in a pool of
to ur 3 - to 6 -week placebo-controlled clinical trials, revealing a statistically significantly greater incidence of weight gain for SEROQUEEL (23\%) COmpared to placebo $6 \%$ )
Laboratory Changes: An assessment of the prermarketing experience tor SEROCUUL suggested that it is associated with asymptomatic increases in SGP and increases in
both total cholesterol and triglycerides (see PRECAUTIOHS). An assessment of hemaiological parameters in short-term, placebo-controlled trials revealed no clinically
mpoutant differences between SERDQUEL and placebo. ECG Changes: Between group comparisons for pooled placebo-controlled trials revealed no statistically
significant SEROaUEL placebo differences in the proportions of patients experiencing However, the proportions of patients meating the criteria for tachlycardia were compared
in four 3 - to 6 -week placebo-controlled clinical trials reveaiing a $1 \%$; $4 / 399)$ incidence tor SEROOUEL compared to $0.6 \%$ ( (1/156) incidence for placebo. SEROOJUL use was slight tendency to tachycardia may be related to SEROQUEL's potential for inducing ot hostatic changes isce PRECAUTIONS). Other Adverse Events Observed Durring
the Pre-Marketing Evaluation of SEROQUEL: Following is a list of COSTART termS that reflect treatment-emergent adverse events as defined in the introduction to the
ADVERSE REACTIONS section reported by patients treated with SEROOUEL at multiple doses $>75$ mgrday during any phase of a trial within the premarketing database of approximately 2200 patients. All reported events are included except those already
listed in Table 1 or elsewhere in labeling, those events for which a drug cause was
remote, and those event terms which were so generat as to be unintormative. It is important to emphasize that, although the events reported occurred during treatment
with SEROQUEL, they were not necessarly caused by t. Events are further categorized by body system and listed in order of decreasing trequency according to the following donly those not already listed in the tabulated results from placebo-controlled trials appear in this listing); intrequent adverse everits are those occurring in $1 / 100$ to
171000 patients; rare events are those occurring in tewrer than $1 / 1000$ patients. Nervous System: Frequent: hypertonia, dysarthria; Infrequent: abnormal dreams,

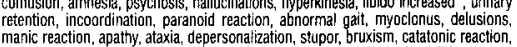

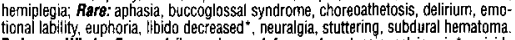
Body as a Whole: Frequent: flu syndrome; Inrequent: neck pain, pelvic pain ${ }^{*}$, suicide attempt, malaise, photosensitivity reaction, chilils, face dedema, monnliasis'; Rare: abdomen enlarged. Digestive System: Frequent: anorexia; Intrequant: increased
saliyation, increased appetite, gamma glutamyl transpeptidase increased, gingivitis, dysphagia, flattlence, gastroentertitis, gasintits, hemorrhoids, stomatilis, thirst, tooth
caries, fecal incontinence, gastroesophageal reflux, gum hemorrhage, mouth urceration, melena, pancreatitis. Cardiovascutar System, Frequent: palpitation; Intrequent: irregular pulse, T wave abnormality, bundele branch biock, cerebrovascular accident deep thrombephlebitis, T wave inversionn; Aars: angina pectoris, atrial tibrillation, AV

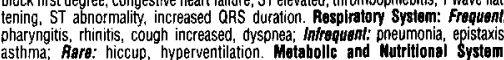

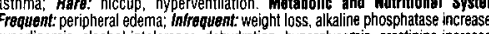
hyperlipemia, alcohol intolerance, dehydration, hyperglycentia, creatinine increased

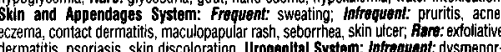

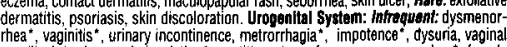

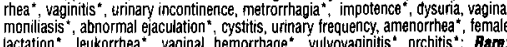
gynecomastia*, nocturia, polyuria, acute kidney tailure. Spectial Senses: infrequent: conijenctivitits, abrormal vision, dry eyes, tinnifus, taste perversion, blepharitis, eye

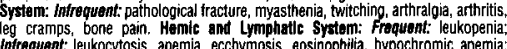

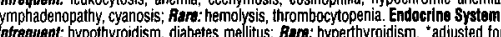

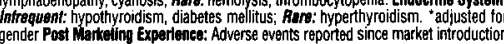
which were temporally related to SEROQUEE therapy include the following: carel leukopenia/neutropenia. It a patient develops a low white cell count consider dispre-existing low white cell count and history of drug induced leukopenia/neutropenia. Controlled Substance Claes: SEROOUEL is not a controlled substance. 


\section{FliGT-UINE TREATMENT FOR SBHIIIOPHRENIIA}

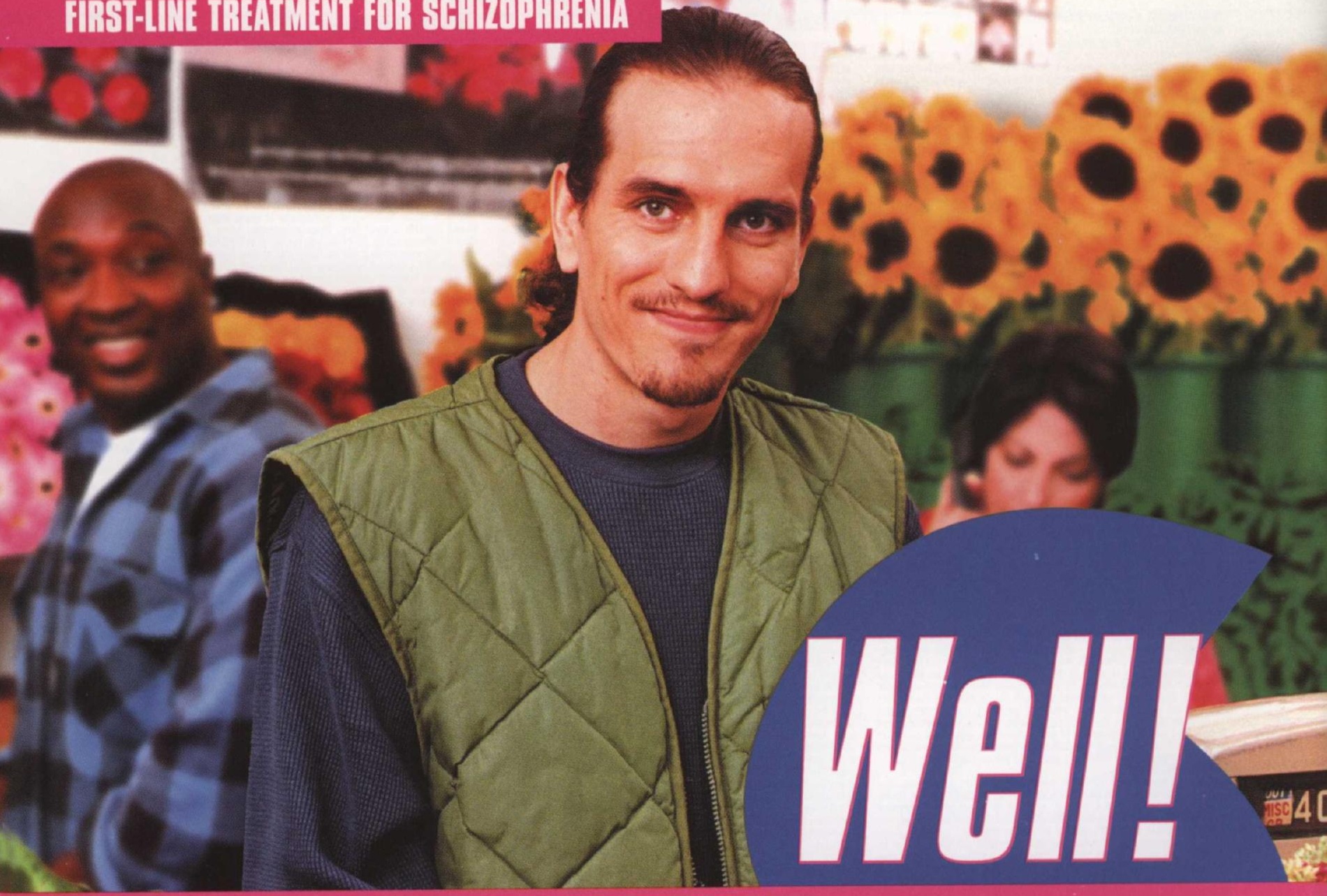

\section{WEIL!}

Éfilibaiby you laok for in an atypiral antipsychotic

- Proven to reduce positive and negative symptoms'

\section{ACGEPTED!}

\section{An exceellent side-efifert profile}

- The only first-line atypical antipsychotic with an EPS*

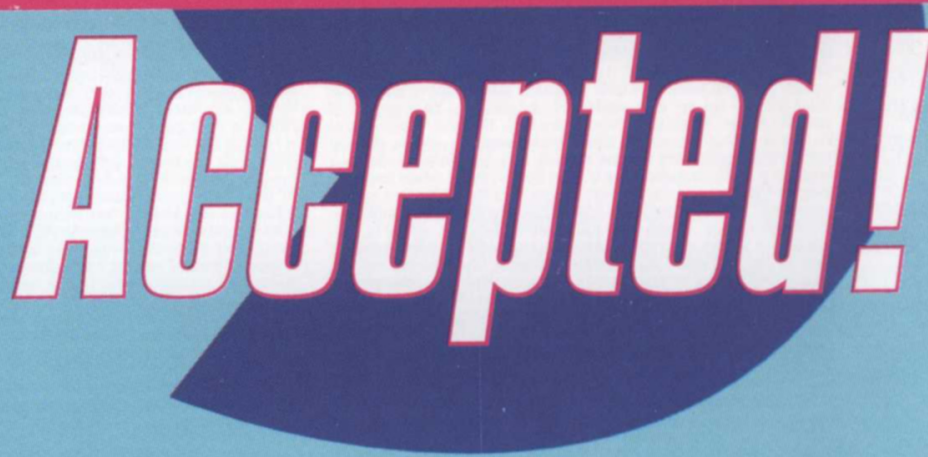

profile no different from placebo across the entire

dosing range (up to $800 \mathrm{mg}$ ).

*Extrapyramidal symptoms.

- The most common adverse events associated with the use of SEROQUEL are dizziness $(10 \%)$, postural hypotension $(7 \%)$, dry mouth $(7 \%)$, and dyspepsia $(6 \%)$. The majority of adverse events are mild or moderate

- As with all antipsychotic medications, prescribing should be consistent with the need to minimize the risk of tardive dyskinesia, seizures, and orthostatic hypotension
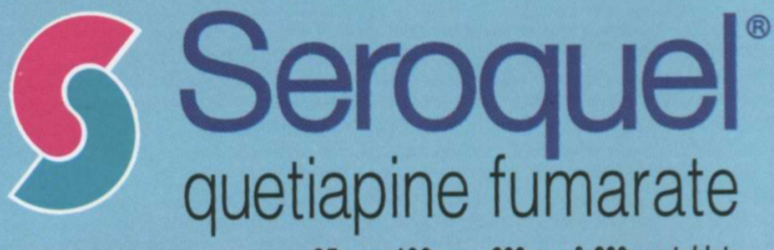

$25 \mathrm{mg}, 100 \mathrm{mg}, 200 \mathrm{mg} \& 300 \mathrm{mg}$ tablets

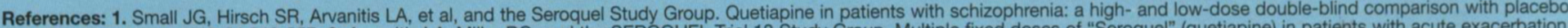

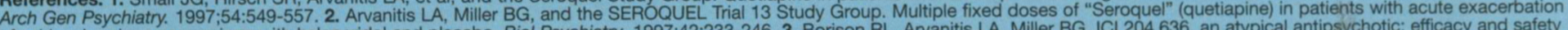

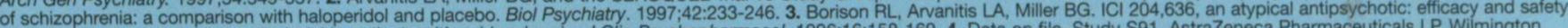
in a multicenter placebo-controlled trial in patients with schizophrenia. J Clin Psychopharmacol. 1996;16:158-169. 4. Data on file, Study S91, A

Delaware. 5. SERROQUEL* (quetiapine fumarate) Prescribing Information, Rev 1/01, AstraZeneca Pharmaceuticals LP, Wilmington, Delaware. 